\title{
Observational Characterization of the Downward Atmospheric Longwave Radiation at the Surface in the City of São Paulo
}

\author{
Eduardo Barbaro, Amauri P. Oliveira, Jacyra SoARes, \\ GeOrgia CODATO, AND MAURício J. FERREIRA
}

Group of Micrometeorology, Department of Atmospheric Sciences, Institute of Astronomy, Geophysics, and Atmospheric Sciences, University of São Paulo, São Paulo, Brazil

PRIMOŽ MLAKAR AND MARIJA Z. BOŽNAR

MEIS d.o.o., Mali Vrh pri Šmarju, Slovenia

JOÃO F. ESCOBEDO

Department of Natural Resources, School of Agronomic Sciences, State University of São Paulo, Botucatu, Brazil

(Manuscript received 1 June 2009, in final form 21 June 2010)

\begin{abstract}
This work describes the seasonal and diurnal variations of downward longwave atmospheric irradiance (LW) at the surface in São Paulo, Brazil, using 5-min-averaged values of LW, air temperature, relative humidity, and solar radiation observed continuously and simultaneously from 1997 to 2006 on a micrometeorological platform, located at the top of a 4-story building. An objective procedure, including 2-step filtering and dome emission effect correction, was used to evaluate the quality of the 9-yr-long LW dataset. The comparison between LW values observed and yielded by the Surface Radiation Budget project shows spatial and temporal agreement, indicating that monthly and annual average values of LW observed in one point of São Paulo can be used as representative of the entire metropolitan region of São Paulo. The maximum monthly averaged value of the $\mathrm{LW}$ is observed during summer $\left(389 \pm 14 \mathrm{~W} \mathrm{~m}^{-2}\right.$; January), and the minimum is observed during winter $\left(332 \pm 12 \mathrm{~W} \mathrm{~m}^{-2}\right.$; July). The effective emissivity follows the LW and shows a maximum in summer $(0.907 \pm 0.032$; January) and a minimum in winter $(0.818 \pm 0.029$; June $)$. The mean cloud effect, identified objectively by comparing the monthly averaged values of the LW during clear-sky days and all-sky conditions, intensified the monthly average LW by about $32.0 \pm 3.5 \mathrm{~W} \mathrm{~m}^{-2}$ and the atmospheric effective emissivity by about $0.088 \pm 0.024$. In August, the driest month of the year in São Paulo, the diurnal evolution of the LW shows a minimum $\left(325 \pm 11 \mathrm{~W} \mathrm{~m}^{-2}\right)$ at $0900 \mathrm{LT}$ and a maximum $\left(345 \pm 12 \mathrm{~W} \mathrm{~m}^{-2}\right)$ at $1800 \mathrm{LT}$, which lags behind (by $4 \mathrm{~h}$ ) the maximum diurnal variation of the screen temperature. The diurnal evolution of effective emissivity shows a minimum $(0.781 \pm 0.027)$ during daytime and a maximum $(0.842 \pm$ $0.030)$ during nighttime. The diurnal evolution of all-sky condition and clear-sky day differences in the effective emissivity remain relatively constant $(7 \% \pm 1 \%)$, indicating that clouds do not change the emissivity diurnal pattern. The relationship between effective emissivity and screen air temperature and between effective emissivity and water vapor is complex. During the night, when the planetary boundary layer is shallower, the effective emissivity can be estimated by screen parameters. During the day, the relationship between effective emissivity and screen parameters varies from place to place and depends on the planetary boundary layer process. Because the empirical expressions do not contain enough information about the diurnal variation of the vertical stratification of air temperature and moisture in São Paulo, they are likely to fail in reproducing the diurnal variation of the surface emissivity. The most accurate way to estimate the LW for clear-sky conditions in São Paulo is to use an expression derived from a purely empirical approach.
\end{abstract}

Corresponding author address: Amauri Oliveira, Atmospheric Sciences Dept., IAG-USP, Rua do Matão 1226, São Paulo, SP 05508-090, Brazil.

E-mail: apdolive@usp.br

DOI: $10.1175 / 2010 J A M C 2304.1$

(C) 2010 American Meteorological Society 


\section{Introduction}

Downward atmospheric longwave radiation fluxes (LW) at the surface play an important role in the airsurface interaction, which can be estimated from radiative transfer models, empirical expressions, and observations. Despite the good performance, radiative transfer models are difficult to use regularly because they require information about the atmospheric thermodynamic state, aerosol load and composition, vertical distribution of moisture, and other greenhouse gases (Ellingson et al. 1991; Dutton 1993; Mlawer et al. 1997; Turner et al. 2004). Comparatively, empirical expressions are easy to apply but they are limited to the conditions of theirs derivations and they also require long-term measurements of radiation fluxes, screen air temperature, and air water vapor pressure to be validated for a particular site and season (Prata 1996; Crawford and Duchon 1999; Iziomon et al. 2003; Finch and Best 2004; Bilbao and de Miguel 2007; Flerchinger et al. 2009). Downward longwave radiation at the surface estimated from satellite data requires a combination of radiative transfer modeling, empirical expression applications, and in situ observations (Garratt 2001; Gupta et al. 1992; Iziomon et al. 2003). Direct observations of LW are more precise when compared with the other techniques, but for heterogeneous surfaces they are less representative. According to Albrecht and Cox (1977), pyrgeometers require special care due to the fact that the sensor emission (dome and case) has to be taken into consideration explicitly. Following the work of Albrecht and Cox (1977), several authors introduced some refinement to the dome emission correction improving the accuracy of LW measurements with commercially available pyrgeometers reducing the error to below 5\% (e.g., Fairall et al. 1998; Payne and Anderson 1999; Philipona et al. 2001, 2004; Burns et al. 2003; Marty et al. 2003).

Despite the importance, measurements of LW at the surface are very rare in Brazil (Duarte et al. 2006; Oliveira et al. 2006). The Group of Micrometeorology of the University of São Paulo, Brazil, started measuring downward longwave radiation at the surface in São Paulo (Fig. 1) in October 1997 (Oliveira et al. 2006). In this work, 5-minaveraged measurements of LW carried out in São Paulo continuously during $9 \mathrm{yr}$, from 1997 to 2006, will be used to characterize the seasonal variation of $\mathrm{LW}$ at the surface.

The city of São Paulo, with about 11 million inhabitants, together with 38 other smaller cities, forms the Metropolitan Region of São Paulo (MRSP). This region, located about $60 \mathrm{~km}$ from the Atlantic Ocean (Fig. 1b), is occupied by 20.5 million inhabitants and has approximately 7 million vehicles. The MRSP has an area of $8051 \mathrm{~km}^{2}$ and it is the largest urban area in South America and one of the 10 largest in the world. Even though pollution is the most
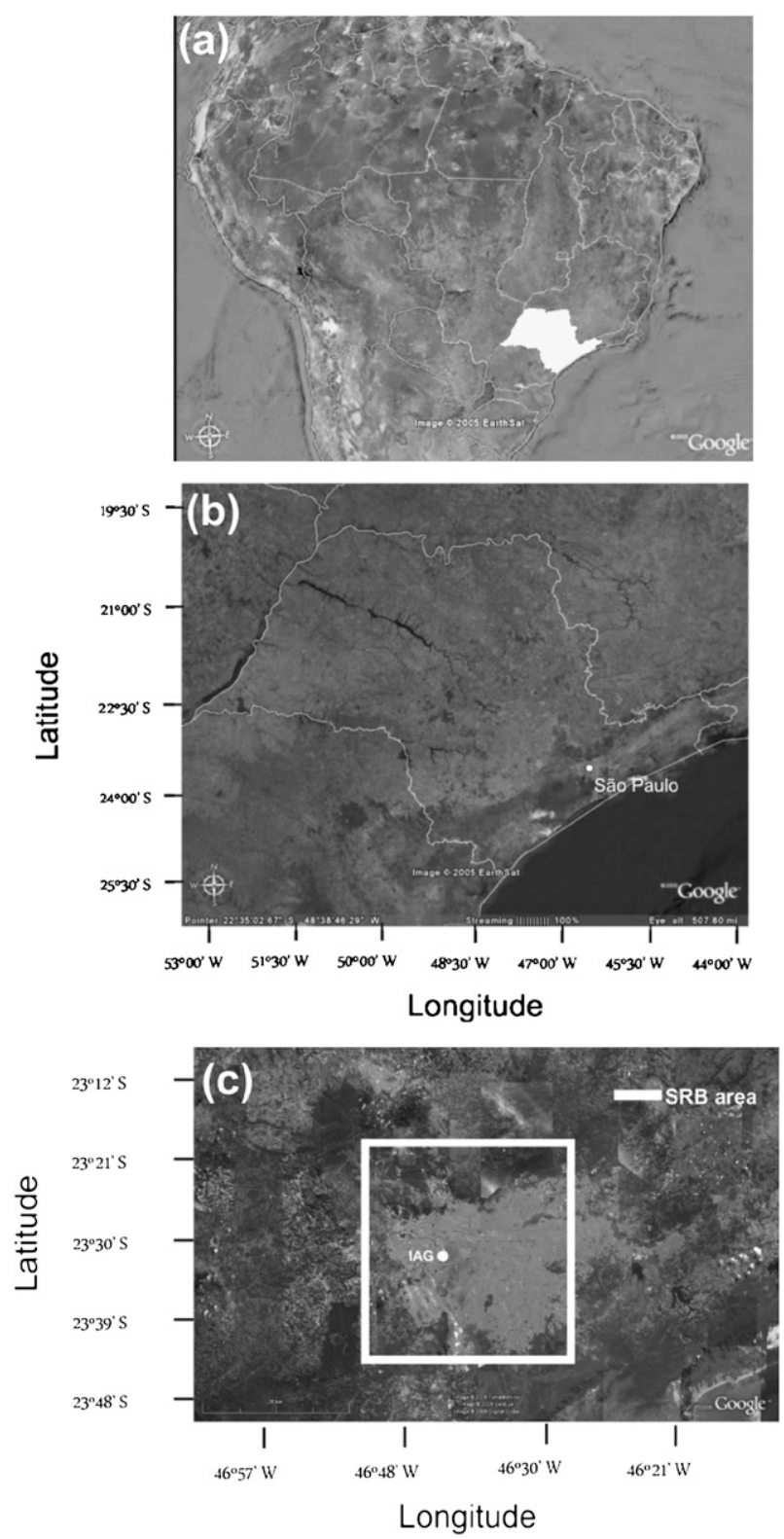

FIG. 1. Geographic position of the (a) state of São Paulo, (b) city of São Paulo, and (c) IAG meteorological station. The SRB area is indicated by a white square.

dramatic environmental problem in the MRSP, the assessment of the pollution impact on the local climate is still incipient. There is evidence that pollution in São Paulo has altered the local climate by affecting the diurnal variation of diffuse, direct, and global solar irradiance components at the surface locally (Oliveira et al. 2002b) and in the regional scale (Codato et al. 2008).

Regional patterns of clouds and moisture also play an important role in the solar radiation features in São Paulo. For instance, comparison between the seasonal variations 
of daily and hourly values of global and diffuse solar radiation at the surface in São Paulo and the rural area in the vicinity, has indicated that São Paulo receives, during clear-sky days, $7.8 \%$ less of global irradiance in August and $5.1 \%$ less in June than rural areas at the same latitude and altitude. On the other hand, São Paulo receives, during clear-sky days, 3.6\% more of diffuse irradiance in August and $15.6 \%$ more in June than rural areas. The seasonal variation of the diurnal cycle confirmed these differences and indicated that they are more pronounced during the afternoon (Codato et al. 2008). The regional differences in solar radiation at the surface are mainly related to the distance from the Atlantic Ocean that in turn determines the spatial and temporal distribution of moisture and clouds in São Paulo. The systematic penetration of the sea breeze during the afternoon in São Paulo brings moisture and maritime aerosol increasing the solar radiation scattering and reducing the intensity of the direct component of solar radiation at the surface (Codato et al. 2008).

The main objective of this work is to characterize the seasonal variation of LW in São Paulo using the available measurements of longwave radiation and other meteorological parameters like air temperature, air relative humidity, and global and diffuse radiations measured at the Institute of Astronomy, Geophysics and Atmospheric Sciences, (IAG), located at the University of São Paulo campus, in the western portion of São Paulo (Oliveira et al. 2002b). Here, a detailed analysis will be carried in an LW dataset to guarantee its quality by removing errors associated with sensor malfunctioning and dome emission effects. In the particular case of pyrgeometer used in São Paulo, the malfunctioning is detected and removed objectively by two-step filtering. The dome emission effect is removed using the neural network technique proposed by Oliveira et al. (2006) and the heat balance equation originally proposed by Albrecht and Cox (1977) and refined by several authors. The corresponding values of global solar radiation, air temperature, and relative humidity are also removed from the dataset to guarantee the consistency of the dataset. In addition, a comparison between in situ observations and satellite estimates of LW are used to investigate whether only one point of observation (IAG) may be used to represent the LW atmospheric emission in the entire MRSP and the existing gaps in the dataset compromise the temporal representativeness of LW measurements carried out in São Paulo.

In the second part of this work, the seasonal and diurnal variations of LW at the surface in São Paulo are addressed and special attention is given to the role played by clouds. Here, the seasonal and diurnal variations of LW are analyzed by comparing the effective emissivity for clearsky and all-sky conditions (Malek 1997; Long and Turner 2008). A general approach concerning validation, use, and development of empirical expressions to estimate LW at the surface for clear-sky days is proposed, which may settle the question concerning the criteria of choice and how to incorporate local characteristics in formulations.

This is accomplished by showing that empirical expressions available in the literature cannot reproduce the diurnal variation of the effective emissivity of São Paulo because they are based on screen temperature and water vapor measurements that do not convey enough information about the local diurnal variation of thermal and moisture stratification. In the diurnal time scale, the contribution of lower layers of the atmosphere to LW at the surface is strongly dependent on the diurnal evolution of the planetary boundary layer (PBL), which, in turn, depends on the surface exchange process. The discrepancy associated with the misrepresentation of the PBL is particularly important during the daytime in areas of complex land used like urban regions. The simplest way to overcome all these difficulties is by developing a purely empirical approach.

A description of the data used in this work, as well the methodology to remove glitches from LW observations and improve their precision using the heat balance equation and neural network technique to correct dome emission effect are described in section 2. This section also includes an evaluation of the spatial and temporal representativeness of LW measurements by comparing monthly and annual values of LW observed in one point and estimated from satellite observations. The characterizations of the seasonal and diurnal variations of $\mathrm{LW}$ in São Paulo are addressed in sections 3 and 4, respectively. In these sections, the seasonal and diurnal variation of LW is analyzed comparing the effective emissivity for clearsky and all-sky conditions. The use and development of empirical expressions for estimating LW are addressed in section 5, and the relevant findings of this work are summarized in section 6 .

\section{Data description}

All meteorological measurements were taken on a micrometeorological platform located at the top of the building at IAG at the University of São Paulo, in the western portion of the city of São Paulo, Brazil (Fig. 1), at $744 \mathrm{~m}$ above mean sea level $\left(23^{\circ} 33^{\prime} 35^{\prime \prime} \mathrm{S}, 46^{\circ} 43^{\prime} 55^{\prime \prime} \mathrm{W}\right)$. The sensors and measurement periods are indicated in Table 1. The measurements were taken with a sampling frequency of $0.2 \mathrm{~Hz}$ and stored as 5-min averages in a datalogger 21X from Campbell Scientific Instruments, Inc. Simultaneously and with the same sampling frequency it also measured the global solar radiation, air temperature, and air relative humidity at the surface level. 
TABLE 1. Sensors and measurement period.

\begin{tabular}{llc}
\hline \hline \multicolumn{1}{c}{ Variable } & \multicolumn{1}{c}{ Sensor } & Period \\
\hline LW, 5-min average & Pyrgeometer, Model PIR, Eppley Laboratory, Inc. & $1997-2006$ \\
Global solar radiation, 5-min average & Pyranometer, Model 8-48, Eppley Laboratory, Inc. & $1997-2006$ \\
Diffuse solar radiation, 5-min average & Pyranometer, Model PSP, Eppley Laboratory, Inc. & $1997-2006$ \\
Air temperature, 5-min average & HMP35C, Vaisala & $1997-2006$ \\
Relative humidity, 5-min average & HMP35C, Vaisala & $1997-2006$ \\
LW, monthly average & Project SRB/NASA & $1998-2004$ \\
\hline
\end{tabular}

The LW has been regularly measured in São Paulo since October 1997 using a pyrgeometer model, Precision Infrared Radiometer (PIR), from Eppley Laboratory, Inc. This instrument performs hemispherical, broadband, infrared radiative flux measurements, using thermopile temperature difference. Its composite transmission window associated with the silicon dome properties is $4-50 \mu \mathrm{m}$ (Philipona et al. 1995; Ji and Tsay 2000). The PIR comes with a battery-powered resistance circuitry that provides voltages that allow estimating the radiative flux contribution due to the case and dome temperatures simultaneously to thermopile output. However, extra channels to record in the datalogger both case and dome temperatures became available only in 15 October 2003. From this date on, dome and case temperatures were used to correct dome emission effects on the pyrgeometer measurements as described in section $2 \mathrm{~b}$. Prior to this date, the pyrgeometer PIR measured only the thermopile output and the neural network procedure was applied to correct the dome effect as described in section $2 \mathrm{c}$.

A pyranometer, model 8-48, built by Eppley Laboratory, Inc., measured global solar irradiance. A pyranometer model, the Precision Spectral Pyranometer (PSP), built by Eppley Laboratory, Inc., and coupled to a shadow ring device measured diffuse solar irradiance (Oliveira et al. 2002a). These sensors have been periodically calibrated using, as a secondary standard, the PSP from Eppley Laboratory, Inc. The calibration consists of running, at least once a year, side by side, both pyranometers continuously during 2-7 days (Oliveira et al. $2002 \mathrm{~b}$ ). A new calibration factor is evaluated by comparing output voltages measured by pyranometers and using, as reference, the calibration factor of the PSP.

Air temperature and air relative humidity were estimated using a pair of thermistor and capacitive sensors from Vaisala. According to the manufacturer, the air temperature and relative humidity are measured with an accuracy of $0.1^{\circ} \mathrm{C}$ and $2 \%$, respectively, for a range of temperature $0^{\circ}-40^{\circ} \mathrm{C}$ and $10 \%-90 \%$.

Sensors measuring LW, global, and diffuse solar radiation; air temperature; relative humidity; and rain are set up $1.5 \mathrm{~m}$ above the surface located at the top of a 4-story building. Therefore, in this work, screen air temperature and water vapor represent the data of $1.5 \mathrm{~m}$ above the roof surface. The LW measurements were carried out without any horizontal obstruction, so they can be considered valid for a sky-view factor equal to 1 (Jonsson et al. 2006).

\section{a. Data quality control}

Figures 2a-c show the raw data from 1997 to 2006 of shortwave radiation (Fig. 2a), air temperature (Fig. 2b), and LW (Fig. 2c). To filter the raw data, a two-step filter was applied. The first step is intended to remove only the physically inconsistent values [i.e., the larger signal incursions in LW (Fig. 2c)] using 0 and $1000 \mathrm{~W} \mathrm{~m}^{-2}$ as thresholds, and removing LW values outside these limits. This procedure removes only the LW data related to the connection malfunctioning or pyrgeometer battery failure. It simultaneously removed all parameters even when the glitches happened only in one of them to make the dataset consistent. This procedure is responsible for removing most of the doubtful data.

However, there were time periods when the pyrgeometer was not totally working because of the battery malfunctioning (initial stages) and the resulting effect on the LW data was more difficult to identify since the pyrgeometer was not totally shut down. Another common problem is related to the accumulation of rain and dust over the sensor. To attenuate the contamination of these problems, a second step consisting of removing LW values located out of the 2 standard-deviation interval centered on the mean value $\left(362 \pm 64 \mathrm{~W} \mathrm{~m}^{-2}\right)$ was applied to the data inspection procedure. The corresponding values of global solar radiation [i.e., shortwave (SW)], air temperature, and air relative humidity were also removed from the dataset when LW was removed in the previous steps.

To guarantee its representativeness in the description of the diurnal cycle, data corresponding to an entire day were removed when four or more 5-min average values were missing. The filtered dataset is indicated in Figs. $2 \mathrm{~d}-\mathrm{f}$. The filtered dataset (Figs. $2 \mathrm{~d}-\mathrm{f}$ ) consists of $64 \%$ (602 134 values for each parameter) of the raw data (Figs. 2a-c). The LW filtered is displayed in Fig. 2f. 

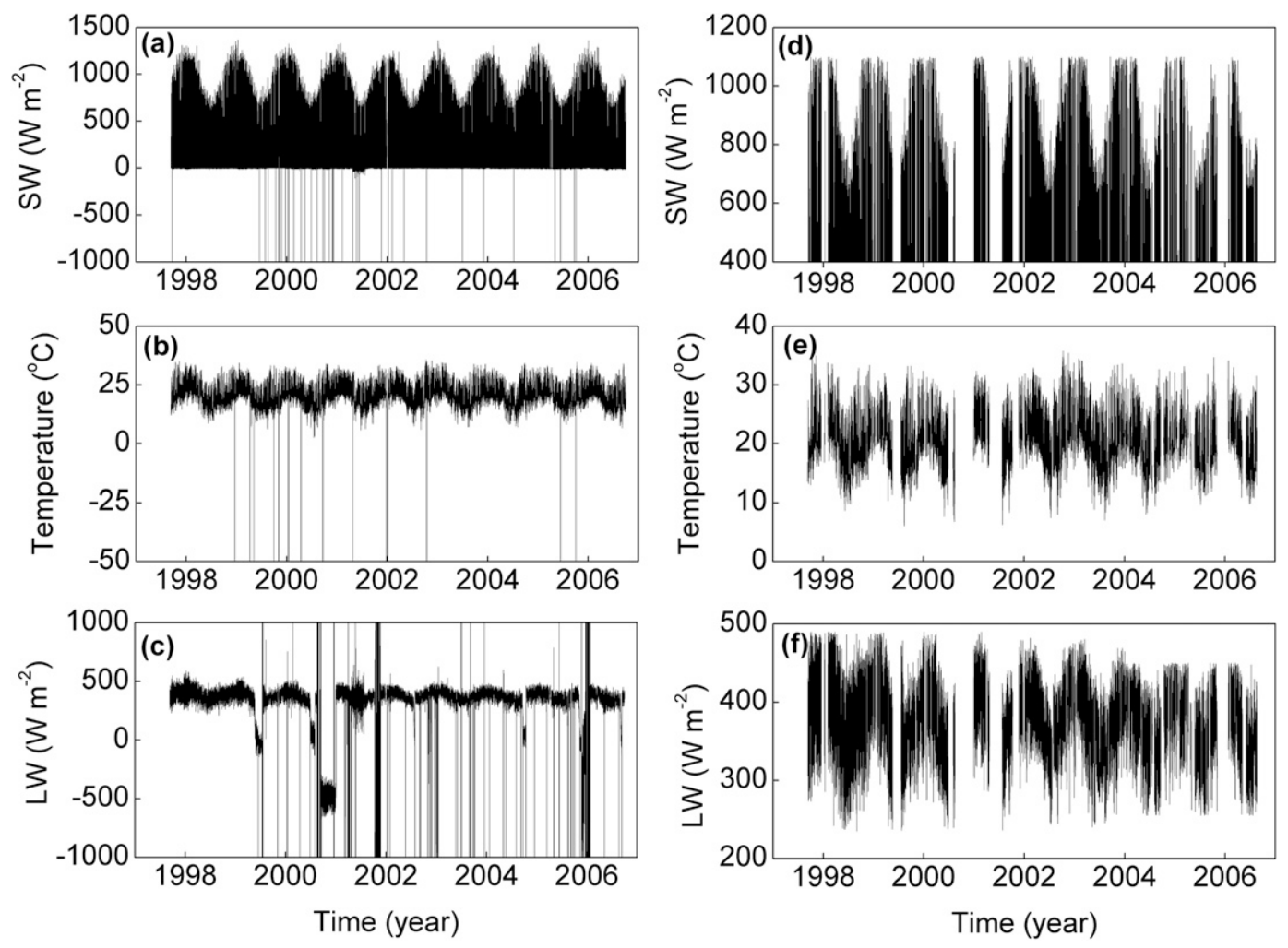

FIG. 2. Time series of raw (a) global solar radiation, (b) air temperature, and (c) LW at the surface. Time series of filtered (d) global solar radiation, (e) air temperature, and (f) LW.

\section{b. Pyrgeometer dome emission effect correction using the heat balance equation}

The atmospheric longwave emission measured by the PIR can be estimated considering the heat balance equation originally proposed by Albrecht and Cox (1977) and modified by Fairall et al. (1998) and Payne and Anderson (1999):

$$
\mathrm{LW}_{\text {CORRECTED }}=\frac{\Delta V}{s_{0}}+\sigma T_{C}^{4}+B \sigma\left(T_{C}^{4}-T_{D}^{4}\right)
$$

where $\mathrm{LW}_{\text {CORRECTED }}$ is the corrected value of longwave radiation; $\Delta V$ is the thermopile voltage; $\sigma$ is the Stefan-Boltzmann constant; $T_{C}$ and $T_{D}$ are, respectively, the case and dome temperatures; and $s_{0}$ and $B$ are calibration factors dependent on the sensor direct calibration. The calibration factor $s_{0}$ is known as the fundamental radiometer sensitivity constant and it depends on the thermopile thermal conductivity, paint emissivity, sensor temperature, and dome characteristic represented by factor $B$. Factor $B$, known as the dome factor, represents the ratio of dome emittance to dome transmittance.

According to Fairall et al. (1998), considering the third term on the right-hand side of Eq. (1) reduces the error to
$3.5 \%$. In this work, simultaneous measurements of LW, $T_{C}$, and $T_{D}$ were available after 15 October 2003. In the case of the pyrgeometer used here (model PIR and serial number 28594F3), the value of $s_{0}$, provided by the manufacturer, is equal to $3.63 \pm 0.04 \mu \mathrm{V} \mathrm{W}^{-1} \mathrm{~m}^{2}$ and the $B$ value is equal to 3.5. Details about the derivation of $s_{0}$ and $B$ for most of the pyrgeometers available commercially can be founded in Albrecht and Cox (1977), Philipona et al. (1995), Fairall et al. (1998), Payne and Anderson (1999), and Burns et al. (2003). The value of $B$ used here (i.e., 3.5) was proposed by Fairall et al. (1998) after analyzing several different calibrations of the PIR.

After 15 October 2003 LW $_{\text {CORRECTED }}$ was estimated using Eq. (1). Before this date, LW was estimated based on the neural network $(\mathrm{NN})$ technique $\mathrm{LW}_{\mathrm{NN}}$ procedure developed by Oliveira et al. (2006) and described in the next section.

\section{c. Pyrgeometer dome emission effect correction using the neural network}

The neural network applied in this case used a training set (learning and optimization dataset) employing data measured during the years 2004 ( 7 days) and 2005 (2 days) corresponding to 2578 observations. The optimization dataset was based on $10 \%$ of randomly selected patterns 
from the original training set and it was used during the training process to periodically test the multilayer perceptron neural network (MLP) performance as the "unknown" dataset to determine its generalization capabilities (Mlakar and Božnar 1997; Gardner and Dorling 1998; Soares et al. 2004). The final network was the one that gave the smallest error on the optimization dataset and not on the training set. These 9 days were chosen based on the heuristic method, from patterns defined as dry, wet, cold, cloudy, and clear-sky days. Based on analysis performed previously by Oliveira et al. (2006), the most relevant parameters for the construction of the dome effect correction were observed longwave radiation, global solar radiation, air temperature, and relative humidity.

According to Oliveira et al. (2006), the standard back propagation algorithm with a learning rate of 0.3 and momentum of 0.5 provided a quick and effective learning of the chosen neural network type-MLP. It should be emphasized that the MLP used here is a three-layer perceptron with a logistic (sigmoid) activation function and back propagation learning algorithm (Božnar and Mlakar 1998; Božnar 2002). The first MLP layer contains 4 neurons, the second layer contains 50 neurons, and the third layer contains 1 neuron.

The time variation of the difference between LW corrected-prior to 15 October 2003 by the NN and after this date by Eq. (1) - and LW filtered LW FILTERED is indicated in the Fig. 3a. As indicated by the vertical black line in Fig. 3a there is no apparent discontinuity in the series after the NN correction. Most of the rectification was negative, confirming that the adjustment applied to pyrgeometer measurements are due to the dome heating (daytime solar radiation). The determination coefficient $R^{2}$ between $\mathrm{LW}_{\mathrm{NN}}$ and $\mathrm{LW}_{\mathrm{CORRECTED}}$ of $99.1 \%$ indicates good match between both datasets for the year 2004 (Fig. 3b). The 7 days randomly selected in 2004 used in the training of the neural network were not included in the dispersion diagram of Fig. 3b. One plausible reason for $\mathrm{LW}_{\mathrm{NN}}$ to overestimate $\mathrm{LW}_{\text {CORRECTED }}$ for low values of atmospheric emission (Fig. 3b) is the fact that the NN corrections applied here do not consider the wind as a predictor. According to Pérez and Allados-Arboledas (1999), under natural or forced ventilation $T_{C}$ and $T_{D}$ get closer and the correction using Eq. (1) reduces. The NN corrections do not recognize this pattern because it is not present in the predictors set. Another possibility is that to correct LW measurements under clear-sky conditions (small LW values) would be necessary to incorporate information about thermal and moisture stratification from the deeper layers, whose signature is not present in the dataset used to train the NN algorithm (screen air temperature, relative humidity, and global solar radiation). The problem concerning the lack of correlation between LW
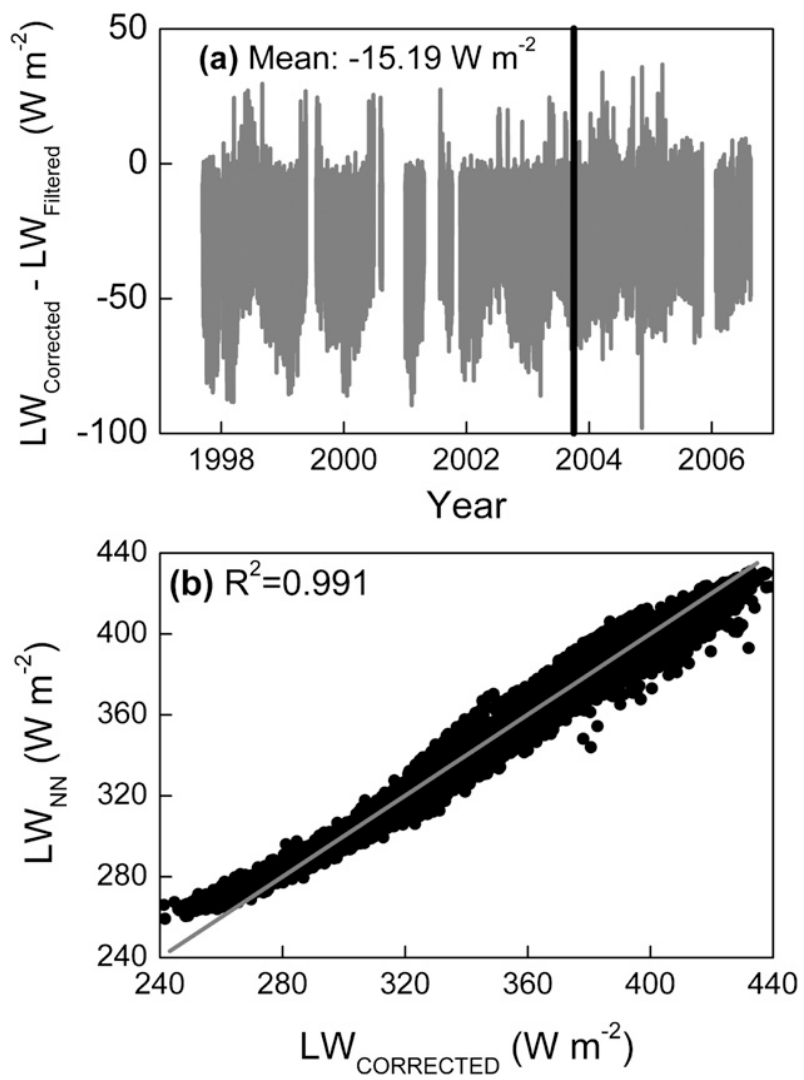

FIG. 3. (a) Time variation of the difference between LW corrected, prior to 15 Oct 2003 by the NN and after this date by the heat balance equation and (b) dispersion diagram of $\mathrm{LW}_{\mathrm{NN}} \mathrm{vs}$ $\mathrm{LW}_{\text {CORRECTED }}$ for 2004. The vertical bar in (a) indicates October 2003. The gray line in (b) indicates the linear fit between $L_{W}$ and LW CORRECTED.

and the screen air temperature and vapor pressure will be addressed in section 4 in the context of effective broadband emissivity in the atmosphere of São Paulo; however, it is important to bring up this question here because this lack of correlation may have an important impact on the methodology of correction of the dome emission effects.

\section{d. Representativeness of $L W$ measurements}

Hereafter, the LW measurements resulting from the application of 2-step data filtering and the dome emission effect correction [using the NN technique before and Eq. (1) after 15 October 2003] will be referred to only as LW measurements.

To evaluate the spatial and temporal representativeness of LW measurements, two comparisons were performed considering monthly and annual averaged values of LW measured at IAG and estimated from the satellite data of the Surface Radiation Budget (SRB) project $\mathrm{LW}_{\mathrm{SRB}}$ of the Atmospheric Science Data Center at the National Aeronautics and Space Administration (NASA; Figs. 4, 5). 


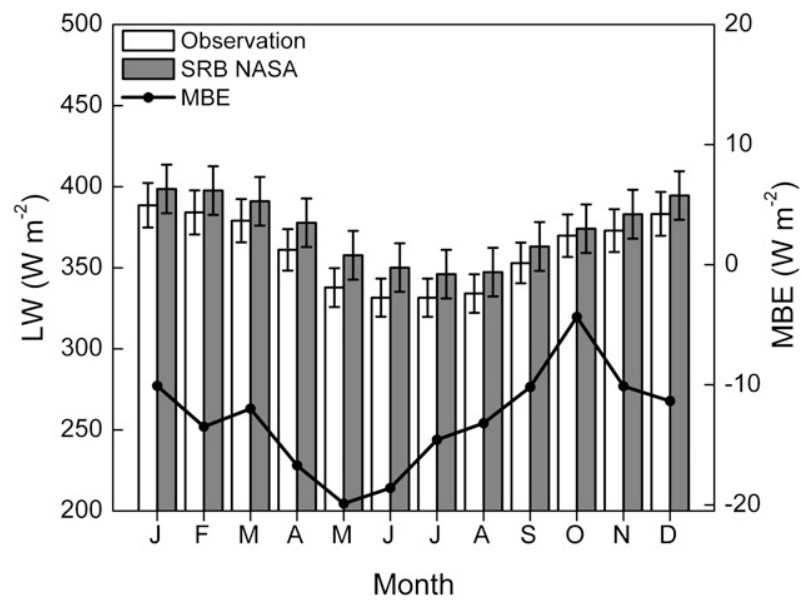

FIG. 4. Seasonal variation of monthly averaged values of LW based on observations carried out in São Paulo during 1997-2006 (white columns) and estimated from SRB during 1998-2004 (gray columns). The error is given by the vertical bars. The MBE (black line) is between the observations and the SRB dataset.

The SRB estimates are derived from the vertical structure of the atmosphere and surface properties' datasets combined with satellite observations and radiation transfer equations for short- and longwave radiation providing several surface and atmospheric parameters with spatial resolution of $1^{\circ}$ latitude by $1^{\circ}$ longitude, with 3-hourly time resolution (Darnell et al. 1983; Gupta et al. 1992, 1993, 1999; Wilber et al. 2006). According to Gupta et al. (1999), among short- and longwave-radiation components yielded by the SRB project, the LW estimates show the largest level of disagreement with respect to in situ observations and general circulation model simulations, with an overall uncertainty of $15 \mathrm{~W} \mathrm{~m}^{-2}$ for monthly average values.

A two-sample test for variance (Snedecor and Cochran 1989; Wilks 2006) was performed using the LW estimated from SRB (1998-2004) to check the spatial representativeness of the seasonal variation of LW observed in São Paulo (1997-2006). For monthly values of $L W$ and $L_{\text {SRB }}$, this test indicates an $f$ value of 1.22 and a $p$ value of 0.75 ; therefore, it is possible to assume, with a $5 \%$ level, that the variances are not significantly different. The statistical parameters, mean bias error (MBE) and root-meansquare error (RMSE), were also used to quantify the compatibility of the LW and $\mathrm{LW}_{\mathrm{SRB}}$ magnitudes. The MBE indicates the magnitude of the mean deviation and provides information about the long-term performance. A small absolute value of MBE is a necessary condition for a good performance; however, it does not suffice because an overestimation can superpose an underestimation. Positive MBE indicates that the observations overestimate SRB and vice versa. The normalized RMSE indicates how well, in percent, the SRB values approach the

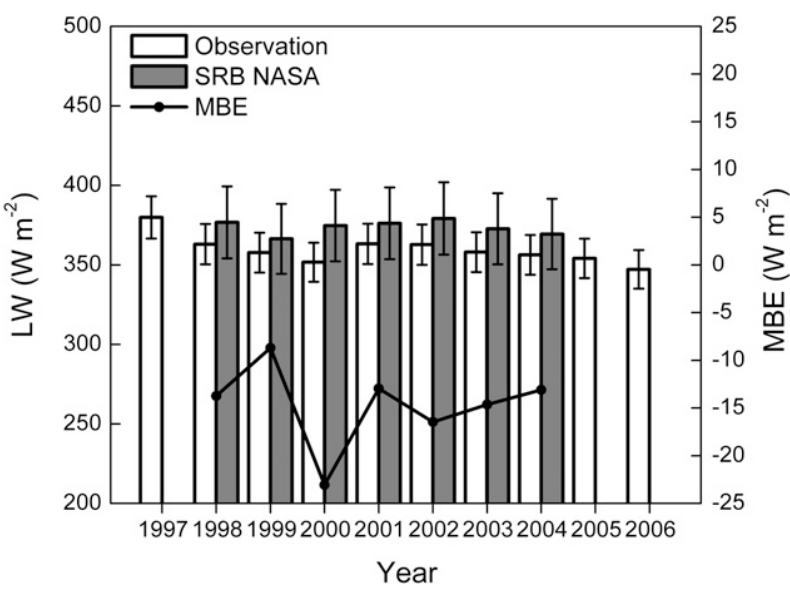

FIG. 5. Time variation of annually averaged values of LW observed at IAG (white columns) during 1997-2006 and estimated from SRB (gray columns) during 1998-2004. The error is given by the vertical bars. The MBE (black line) is between the observations and the SRB dataset.

observations, providing information about short-term performance, considering that RMSE values permit a term-by-term comparison of the standard deviation between datasets. In general, small RMSEs are associated with good estimates (Targino and Soares 2002).

In the specific case of São Paulo, a negative mean $\operatorname{MBE}\left(-12.9 \mathrm{~W} \mathrm{~m}^{-2}\right)$ and a small normalized mean RMSE $(3.6 \%)$ indicate that the SRB values slightly overestimate the observed values (Table 2). One possible reason for this discrepancy is that $\mathrm{LW}_{\mathrm{SRB}}$ depends on the cloud-base height estimates, which according to Gupta et al. (1992) is not precisely estimated in the SRB

TABLE 2. Monthly averaged values of LW, MBE, the number of LW data values available in each month, and the corresponding data fraction. Observation begins on 1 Oct 1997 and ends on 31 Aug 2006. MBE is estimated with respect to $\mathrm{LW}_{\text {SRB }}$. The $\mathrm{LW}$ errors were obtained by Gaussian error propagation of statistical and sensor errors.

\begin{tabular}{lcccc}
\hline \hline \multicolumn{1}{c}{ Month } & LW $\left(\mathrm{W} \mathrm{m}^{-2}\right)$ & $\begin{array}{c}\text { MBE } \\
\left(\mathrm{W} \mathrm{m}^{-2}\right)\end{array}$ & $\begin{array}{c}\text { No. of 5-min } \\
\text { values }\end{array}$ & $\begin{array}{c}\text { Data fraction } \\
(\%)\end{array}$ \\
\hline January & $388.6 \pm 13.7$ & -10.1 & 123 & 44.1 \\
February & $384.2 \pm 13.6$ & -13.5 & 158 & 62.7 \\
March & $379.0 \pm 13.4$ & -12.0 & 228 & 81.7 \\
April & $361.1 \pm 12.8$ & -16.7 & 213 & 78.9 \\
May & $337.8 \pm 12.0$ & -19.9 & 165 & 59.1 \\
June & $331.6 \pm 11.7$ & -18.6 & 192 & 71.1 \\
July & $331.5 \pm 11.8$ & -14.6 & 160 & 57.3 \\
August & $334.1 \pm 11.8$ & -13.2 & 221 & 79.2 \\
September & $352.9 \pm 12.5$ & -10.2 & 183 & 67.8 \\
October & $369.8 \pm 13.1$ & -4.3 & 189 & 67.7 \\
November & $372.9 \pm 13.2$ & -10.1 & 132 & 48.9 \\
December & $383.2 \pm 13.6$ & -11.3 & 129 & 46.2 \\
\hline
\end{tabular}


TABLE 3. Annual averaged values of LW, MBE, the number of LW data values available in each year, and the corresponding data fraction. Data fraction of the available data corresponding to summer (December-February) and winter (June-August) periods for each

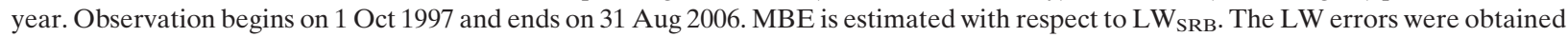
by Gaussian error propagation of statistical and sensor errors.

\begin{tabular}{|c|c|c|c|c|c|c|}
\hline Year & $\mathrm{LW}\left(\mathrm{W} \mathrm{m}^{-2}\right)$ & $\begin{array}{c}\mathrm{MBE} \\
\left(\mathrm{W} \mathrm{m}^{-2}\right)\end{array}$ & $\begin{array}{c}\text { No. of 5-min } \\
\text { values }\end{array}$ & $\begin{array}{c}\text { Data } \\
\text { fraction }(\%)\end{array}$ & $\begin{array}{l}\text { Summer data } \\
\text { fraction }(\%)\end{array}$ & $\begin{array}{l}\text { Winter data } \\
\text { fraction }(\%)\end{array}$ \\
\hline 1997 & $379.9 \pm 13.3$ & - & 23168 & 22.0 & 16.6 & 0 \\
\hline 1998 & $363.0 \pm 12.7$ & -13.7 & 84248 & 80.1 & 39.8 & 97.7 \\
\hline 1999 & $357.7 \pm 12.5$ & -8.7 & 65560 & 62.4 & 53.0 & 44.5 \\
\hline 2000 & $351.6 \pm 12.3$ & -23.1 & 41650 & 39.6 & 33.1 & 41.2 \\
\hline 2001 & $363.2 \pm 12.7$ & -13.0 & 51444 & 48.9 & 69.5 & 40.2 \\
\hline 2002 & $362.7 \pm 12.7$ & -16.5 & 88921 & 84.6 & 67.4 & 91.3 \\
\hline 2003 & $358.0 \pm 12.5$ & -14.6 & 88014 & 83.7 & 66.2 & 92.3 \\
\hline 2004 & $356.3 \pm 12.5$ & -13.1 & 70404 & 67.0 & 55.2 & 69.4 \\
\hline 2005 & $354.1 \pm 12.4$ & - & 47632 & 45.3 & 27.5 & 71.5 \\
\hline 2006 & $347.2 \pm 12.2$ & - & 41093 & 39.1 & 24.3 & 73.7 \\
\hline
\end{tabular}

dataset. The monthly variation of the MBE (Fig. 4, Table 2) indicates that the $\mathrm{LW}_{\mathrm{SRB}}$ values slightly overestimate the LW during the whole year, presenting larger values in May and smaller values in October. The MBE values, however, are similar to the errors involved in the LW $(3.5 \%)$ and $\mathrm{LW}_{\mathrm{SRB}}\left(15 \mathrm{~W} \mathrm{~m}^{-2}\right)$. Thus, from the climate point of view the measurements carried out in the IAG can be considered representative of the entire MRSP describing the seasonal variation of LW above the urban canopy (Fig. 1c). The consistency between observation and SRB estimates indicates that the 2-step filtering procedure carried out in the observations (section 2a), where $36 \%$ of the original dataset was removed, did not introduce any significant bias in the seasonal representation of LW in São Paulo.

The annual LW measurements started in October 1997. Therefore, excluding 1997, the maximum difference between $\mathrm{LW}$ annual values is around $16 \mathrm{~W} \mathrm{~m}^{-2}$ (i.e., the LW annual mean is maximum in 2001 and minimum in 2006). Considering that observations in 2006 finished in August, it is expected that the LW mean in 2006 and the LW annual difference appear slightly underestimated and overestimated, respectively (Table 3).

The number of observations during summer (DecemberFebruary) and winter (June-August) is not the same (Table 3). The largest fractions of valid observations occurred during the winter months, between 1998 and 2006 (except in 1999 and 2001); however, considering the number of observations in the summer period (robustness) and the heterogeneity in the data distribution, it can be assumed that both summer and winter are well represented in the dataset.

The annual observations are validated using the $\mathrm{LW}_{\mathrm{SRB}}$ values because the SRB dataset presents almost no gaps during the investigated period.
The test for variance of annual values of LW and $\mathrm{LW}_{\mathrm{SRB}}$ indicates an $f$ value of 3.98 and a $p$ value of 0.11 , allowing that, at the $5 \%$ level, the two variances are not significantly different. The mean $\operatorname{MBE}\left(-14.7 \mathrm{~W} \mathrm{~m}^{-2}\right)$ and mean RMSE (4.1\%) values indicate that the SRB data slightly overestimate the observed values (Table 3).

The MBE annual values show a small time variation with $\mathrm{LW}_{\mathrm{SRB}}$ always overestimating the observed $\mathrm{LW}$ (Table 3, Fig. 5). The only exception is the year 2000 when a large amount of data was removed in the data inspection procedure (section 2a and Figs. 2c,f).

In short, from the climate point of view the LW measurements carried out in the IAG describe the annual variation of longwave radiation in São Paulo. The constancy and consistency presented by the difference bias indicate that the SRB dataset may be a good indicator of data quality, providing useful information about changes over time in the performance of sensors used in in situ long-time observations.

\section{Seasonal variation of $L W$ in São Paulo}

Considering that the mean annual values of LW (Fig. 5) remained practically constant, this work will focus on the description of the seasonal and diurnal variations of $\mathrm{LW}$ in São Paulo.

São Paulo's climate-typical of subtropical regions of Brazil-is characterized by a dry winter during JuneAugust and a wet summer during December-March (Oliveira et al. 2003). The minimum values of monthly averaged daily temperature and relative humidity occur in July and August $\left(16^{\circ} \mathrm{C}\right.$ and $74 \%$, respectively), and the minimum monthly accumulated precipitation occurs in August $(35 \mathrm{~mm})$. The maximum value of monthly averaged daily temperature occurs in February $\left(22.5^{\circ} \mathrm{C}\right)$ and the maximum value of monthly averaged daily relative 


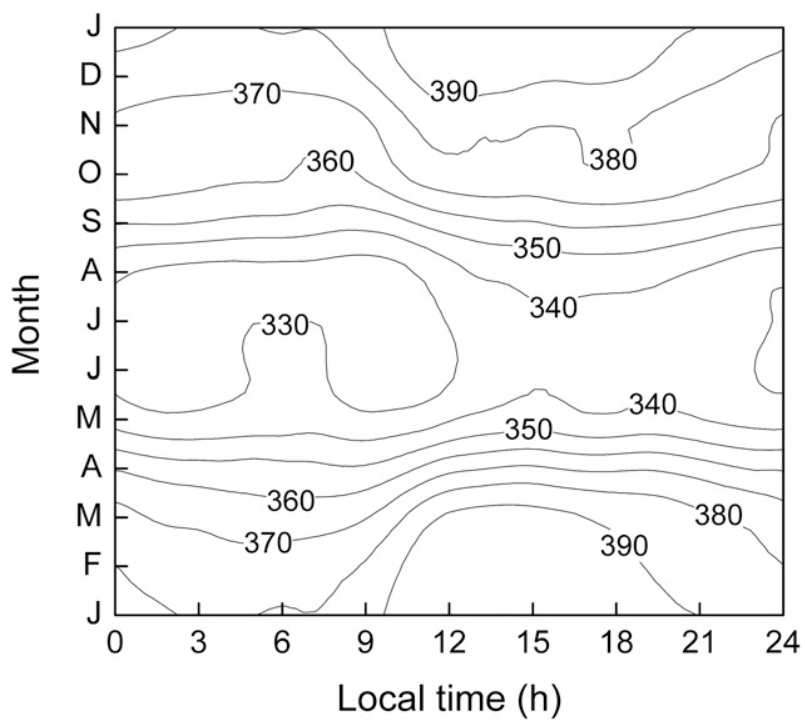

FIG. 6. Seasonal variation of the diurnal evolution of monthly averaged hourly values of $\mathrm{LW}\left(\mathrm{W} \mathrm{m}^{-2}\right)$.

humidity occurs from December through January and from March through April (80\%). The seasonal distribution of surface wind speed indicates that the São Paulo urban area is characterized by light winds throughout the year, with intensity varying between 0.5 (January and May) and $1.5 \mathrm{~m} \mathrm{~s}^{-1}$ (September-October), preferentially from the north-northeast.

The seasonal variation of $\mathrm{LW}$ values is consistent with that expected for the climate of São Paulo described above. The LW maximum during summer $\left(389 \pm 14 \mathrm{~W} \mathrm{~m}^{-2}\right.$, January) is a result of the maximum in the temperature, water vapor, and cloud activity. The $\mathrm{LW}$ minimum during winter (332 $\pm 12 \mathrm{~W} \mathrm{~m}^{-2}$; July) occurs at the driest and cold period of the year, when there is little cloud activity (Fig. 4). The effective emissivity follows the LW and shows a maximum in summer $(0.907 \pm 0.032$; January $)$ and a minimum in winter $(0.818 \pm 0.029$; June $)$.

The LW variations during December, January, and February $\left(0.5 \mathrm{~W} \mathrm{~m}^{-2}\right)$ and June, July, and August $\left(1.3 \mathrm{~W} \mathrm{~m}^{-2}\right)$ are smaller than the variations during the transition periods (autumn: $-20.6 \mathrm{~W} \mathrm{~m}^{-2}$; spring: $10.1 \mathrm{~W} \mathrm{~m}^{-2}$ ).

The seasonal variation of monthly averaged hourly values of LW in MRSP reflects the combination of local climate patterns of air temperature, moisture, and clouds (Fig. 6). The LW observed in São Paulo shows a maximum of $389 \pm 14 \mathrm{~W} \mathrm{~m}^{-2}$ during the summer daytime (January at $1100 \mathrm{LT}$ ) and a minimum of $332 \pm 11 \mathrm{~W} \mathrm{~m}^{-2}$ during the winter daytime (June at 1000 LT). The local maximum ( $\mathrm{LW}>330 \mathrm{~W} \mathrm{~m}^{-2}$ ) observed during MayJune during the dawn period may be related to the fog formation. This pattern is not observed during other

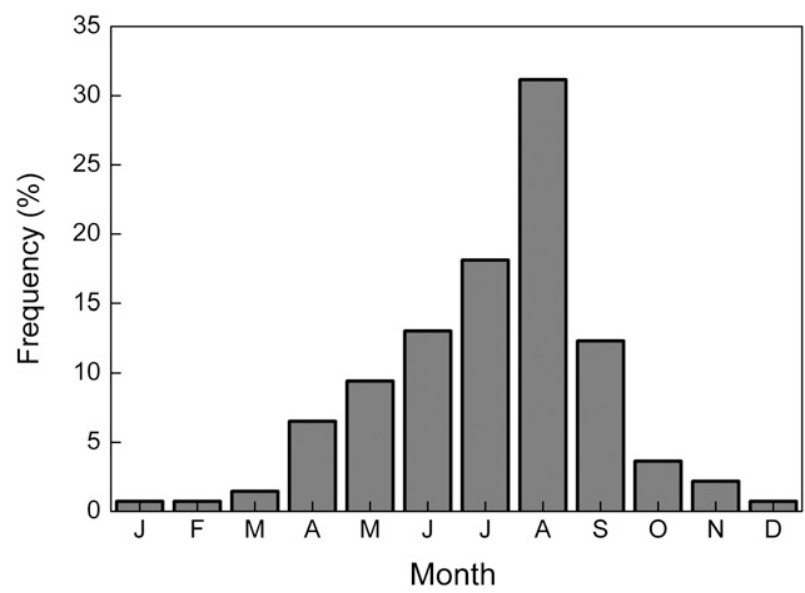

FIG. 7. Seasonal variation of clear-sky day frequency in São Paulo between 1997 and 2006.

winter months because the moisture content of the atmosphere becomes progressively smaller reaching a minimum in August.

\section{Mean cloud effect}

Based on Malek (1997) and Long and Turner (2008), a subset of LW measurements including only clear-sky days was used to investigate the mean cloud effect on the LW radiation in São Paulo, comparing the LW observed under clear sky with the LW considering all-sky conditions.

It should be pointed out that when comparing clear days to all days, the cloud effect is not totally isolated because partly cloudy days and clear times are included in the averages. Unfortunately, it was not possible to isolate completely the cloud effect because independent information about cloud cover was not available at the site. However, most of the mean cloud effects identified here will not qualitatively change by using a more precise way to isolate the contribution of clouds.

Following the diurnal variation of global and diffuse solar irradiances at the surface it is possible, by visual inspection, to identify days when the sky was not significantly covered by clouds. Here, a clear-sky day was considered when the curves of the diurnal variation of global and diffuse solar irradiances are simultaneously smooth and have a distinct separation early in the morning and come together only at the end of the day. Between 1997 and 2006138 days were identified satisfying the clearsky conditions described above. The monthly frequency distribution of clear-sky days during 1997-2006 are indicated in Fig. 7 for São Paulo. The seasonal distribution indicates a maximum frequency during winter and a minimum during summer. As expected, the largest number of clear-sky days occurs in August, which is the driest month of the year. 

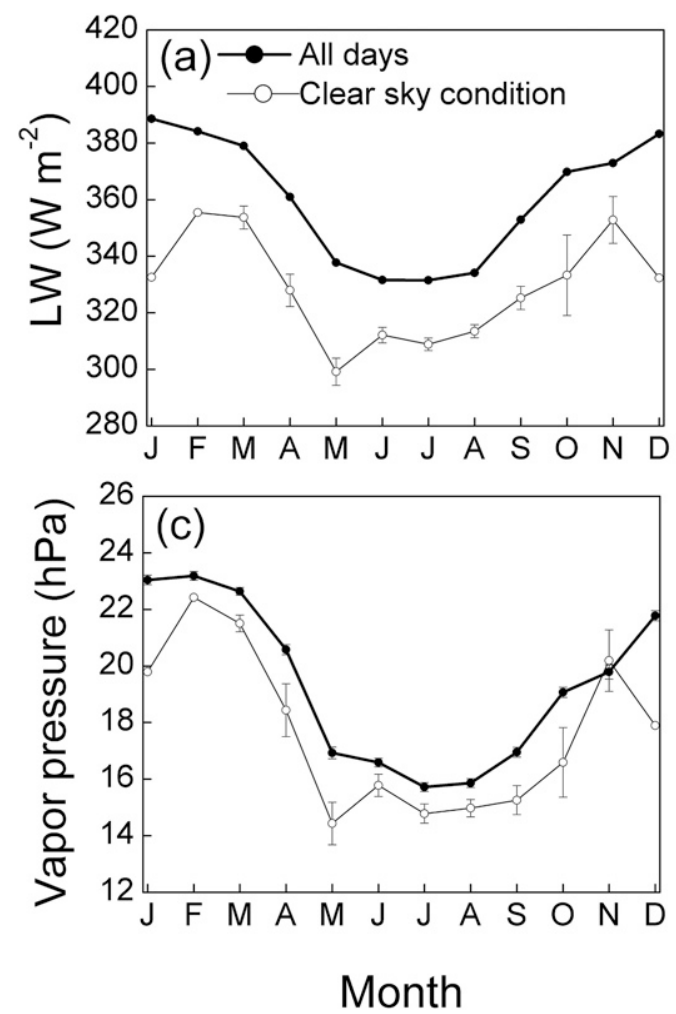
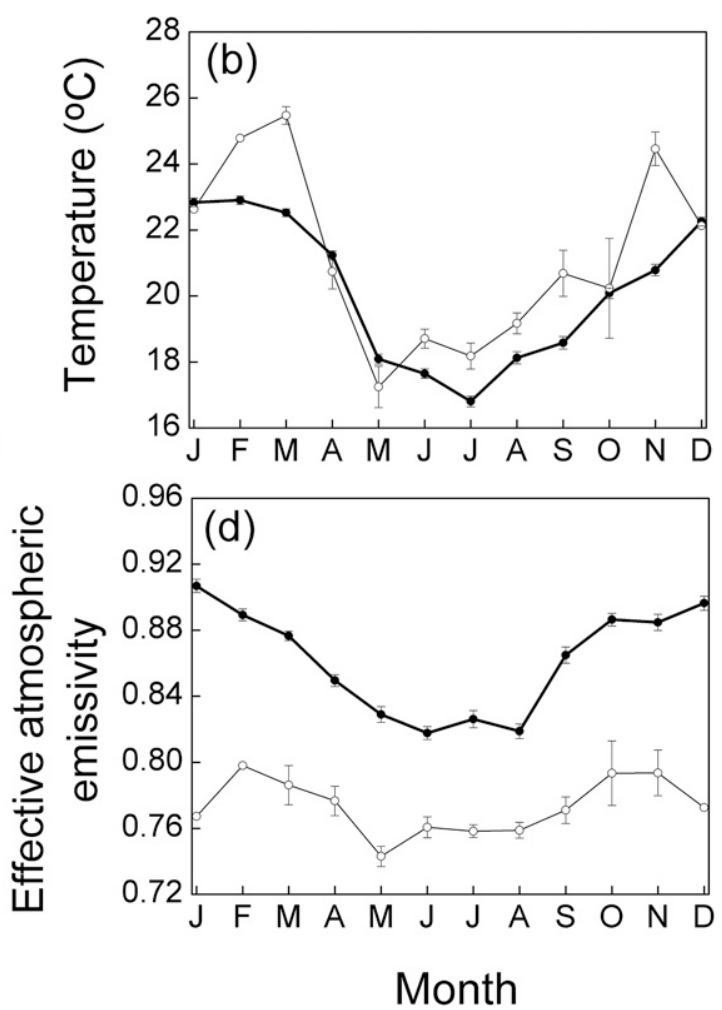

FIG. 8. Seasonal variation of monthly averaged values of (a) LW, (b) air temperature, (c) air vapor pressure, and (d) effective atmospheric emissivity at the surface. The solid circles indicate all days (all-sky conditions) and the open circles indicate clear-sky days. The error is given by the vertical bars.

The method to select clear-sky days uses global and diffuse radiations at the surface and does not distinguish layers of high clouds. However, according to Dürr and Philipona (2004), the presence of high clouds will not affect LW measured at the surface because most of the longwave downward atmospheric emission $(90 \%)$ comes from the first $1000 \mathrm{~m}$ of the atmosphere.

The seasonal variation of monthly averaged values of $\mathrm{LW}$, air temperature, air vapor pressure, and atmospheric effective emissivity, considering all days and clear-sky days, are indicated in Fig. 8.

The effective emissivity is defined as broadband effective emissivity $\mathrm{LW} / \sigma T^{4}$, where $T$ is the air temperature measured at screen level varying in most of the cases between 1.5 and $2 \mathrm{~m}$ above the surface (Prata 1996; Niemelä et al. 2001; Iziomon et al. 2003; Jonsson et al. 2006). The effective emissivity is seen as a bulk atmospheric property that indicates the capability of the lower layers of the atmosphere to emit downward longwave radiation at the surface as a consequence of their composition and thermal stratification (Brunt 1932; Brutsaert 1975; Alados-Arboledas and Jimenez 1988; Malek 1997; Long and Turner 2008; Gröbner et al. 2009).
Clear-sky averages are statistically significant only between April and September when the number of clearsky days are larger than 5\% (Fig. 7). The presence of clouds, on average, increases the LW (Fig. 8a), in $32.0 \pm$ $3.5 \mathrm{~W} \mathrm{~m}^{-2}\left(2.76 \pm 0.30 \mathrm{MJ} \mathrm{m}^{-2}\right.$ day $\left.^{-1}\right)$. The presence of clouds may also be associated with air temperature about $1.05^{\circ} \pm 0.41^{\circ} \mathrm{C}$ lower (Fig. 8b) and vapor pressure about $1.67 \pm 0.35 \mathrm{hPa}$ higher (Fig. 8c). The clouds also increase the atmospheric effective emissivity (Fig. 8d). The averaged cloud contribution to clear-sky effective emissivity is equal to $0.088 \pm 0.024$.

\section{Diurnal variation of $L W$ in São Paulo}

Figure 9 considers the observations carried out in São Paulo only in August, the month with the largest number of clear-sky days, (Fig. 7). When only clear-sky days are considered, the diurnal variation of LW shows a larger amplitude, but smaller intensity (Fig. 9a), indicating that the presence of clouds not only increases the intensity of $\mathrm{LW}\left(325 \pm 11 \mathrm{~W} \mathrm{~m}^{-2}\right.$ at $0900 \mathrm{LT}$ and $345 \pm 12 \mathrm{~W} \mathrm{~m}^{-2}$ at $1800 \mathrm{LT}$ ), because clouds emit in the atmospheric window, but also decreases its diurnal cycle amplitude, as a result of the cloud-base temperature that, on average, 

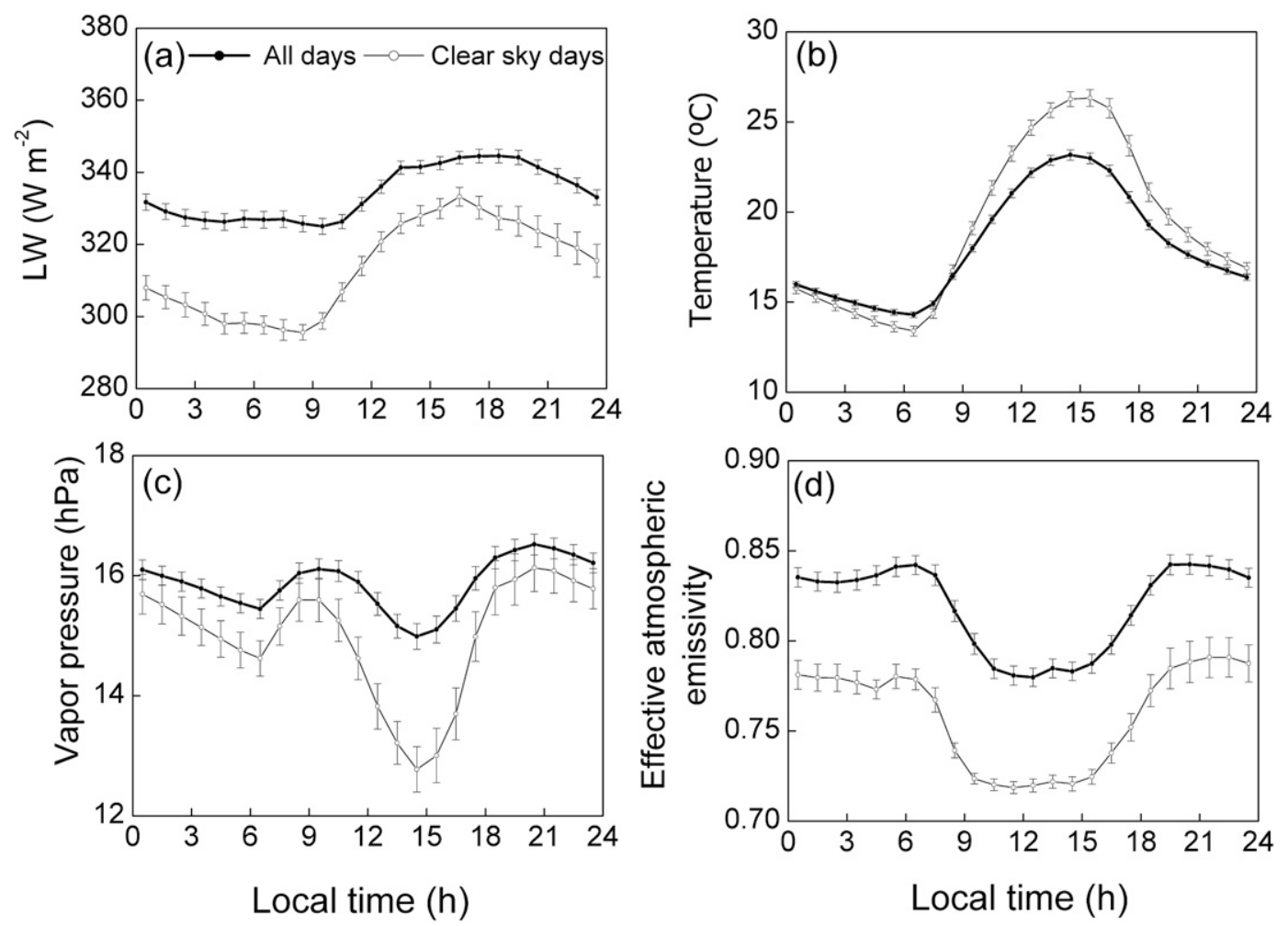

FIG. 9. Diurnal variation of monthly averaged hourly values of (a) LW, (b) air temperature, (c) air vapor pressure, and (d) effective atmospheric emissivity at the surface. The solid circles indicate the monthly averaged hourly values for August of the entire dataset. The open circles indicate the monthly averaged values for clear-sky day observations for August of the entire dataset. The error is given by the vertical bars.

does not vary much during the day. Air temperature and water vapor differences between all and clear days are concentrated during the daytime when clear-sky values of air temperature increases and water vapor decreases more than for all-sky conditions (Figs. 9b,c).

The differences in the effective emissivity remain relatively constant and equal to $0.060 \pm 0.007$, or about $7 \% \pm 1 \%$ during the entire day (Fig. $9 \mathrm{~d}$ ), indicating that the presence of clouds mainly increases the effective emissivity values but do not alter its pattern.

Changes in air temperature (Fig. 9b) and water vapor (Fig. 9c) patterns, considering all-sky and clear-sky days, seem to not alter the effective emissivity pattern (Fig. 9d). Furthermore, the effective emissivity variation is modulated by the water amount variation during the end of the convective (1500-1800 LT) and nighttime periods (18000600 LT). During the convective period (0600-1500 LT) the effective emissivity seems to change with nonlocal effects (e.g., erosion of the surface inversion layer temperature and the early morning peak in latent heat flux).

The daytime drops in the effective emissivity (Fig. 9d), observed in both clear-sky and all-sky conditions, can be explained in terms of day and night contrast of the lower atmosphere stability. During the daytime, even in the presence of clouds, the diurnal variation of the convective PBL alters the stability in the first $2 \mathrm{~km}$ over São Paulo. This effect is a robust feature of the local atmosphere present in both the clear sky and all sky. The diurnal variation in the effective emissivity for the all-sky condition is basically a result of the PBL effects induced by the presence of 138 clear-sky days and a large numbers of clear-sky periods in the partially cloudy days existing in dataset. Observational works indicate that the PBL height in São Paulo varies from a maximum of $200 \pm 100 \mathrm{~m}$ at nighttime to a maximum of $2000 \pm 500 \mathrm{~m}$ during the daytime (Nair et al. 2004; Marciotto 2008).

According to Gröbner et al. (2009), measurements of LW at the surface contain enough information about the PBL to infer the thermal vertical structure of the lower layers by just comparing broadband LW measurements and LW in the atmospheric window. Therefore, the effective emissivity better represents the PBL upper layers than the surface parameters.

The screen vapor pressure and air temperature are equally important in the definition of the diurnal variation of effective emissivity during nighttime because the 
vertical stratification at nighttime is confined to surface adjacent layers.

As pointed out by Alados-Arboledas and Jimenez (1988), the diurnal variation of the effective emissivity should include the time variation of the vertical thermal stratification. The delay between the daytime maximum of the monthly average temperature $\left(23.2^{\circ} \pm 0.1^{\circ} \mathrm{C}\right.$ at $1800 \mathrm{LT})$ and $\mathrm{LW}\left(345 \pm 12 \mathrm{~W} \mathrm{~m}^{-2}\right.$ at $\left.1400 \mathrm{LT}\right)$ is caused by the time necessary to erode the surface inversion during the morning (Figs. 9a,b), indicating that the correlation between air temperature at the screen level and LW is phased out ( $4 \mathrm{~h}$ in the case of August).

\section{Estimating $L W$ for clear-sky conditions in São Paulo}

The main objective of this section is to find a simple method to estimate LW in clear-sky conditions in São Paulo, which could be easily implemented in algorithms to evaluate the energy balance at the surface in urban areas (Arnfield and Grimmond 1998; Martilli et al. 2002; Offerle et al. 2003; Karam et al. 2009).

For better accuracy, the method needs to take into account the effective emissivity dependence on temperature and moisture vertical structures of the shallower layers of the atmosphere that contribute to most of the LW at the surface (Dürr and Philipona 2004).

It was observed in the previous sections that the relationships between effective emissivity (Fig. 9d) and screen air temperature (Fig. 9b) and between effective emissivity and water vapor (Fig. 9c) are rather complex. During the night, when the planetary boundary layer is shallower, the effective emissivity can be estimated by screen parameters. During the day, the relationship between effective emissivity and screen parameters is more complex because it varies from place to place and depends on PBL process (Alados-Arboledas and Jimenez 1988; Crawford and Duchon 1999; Dürr and Philipona 2004; Long and Turner 2008; Gröbner et al. 2009).

Following previous authors, for example, Ellingson et al. (1991), Dutton (1993), Mlawer et al. (1997), and Turner et al. (2004), the most accurate way to estimate LW for clear conditions is using a radiative transfer equation (RTE); however, the scarcity of appropriate information precludes the use of the RTE approach. For instance, in the urban area of the city of São Paulo, radiosondes are carried out twice a day and estimating hourly values of LW will require value interpolations, which will introduce a large uncertainty in the LW estimates.

An alternative to estimate LW at the surface for clearsky conditions is using simple empirical expressions (Brunt 1932; Swinbank 1963; Brutsaert 1975; Prata 1996; Dilley and O'Brien 1998; Crawford and Duchon 1999; Niemelä et al. 2001; Iziomon et al. 2003; Finch and Best 2004; Bilbao and de Miguel 2007; Flerchinger et al. 2009). However, choosing the best expression among those available in the literature is not an easy task, leading to concerns about the criteria of choice, validation procedure, and how to incorporate local characteristics in the formulation.

Given the above concerns, it becomes clear that making additional observations to perform RTE calculations compete, in terms of difficulty and limitations, with selecting and applying the best empirical expression relative to the desired accuracy applications. Therefore, a more appropriate method to estimate LW is using a purely empirical approach (PEA), where a nonlinear fit is performed through LW values without specifying the relationship between LW and screen parameters. The result of this approach is indicated below [see Eq. (2)] and it will be shown that this expression performs better than other LW empirical expression available in the literature. In addition, the use of the PEA methodology implies a better reproduction of the diurnal variation of the effective emissivity observed in São Paulo:

$$
\begin{aligned}
\mathrm{LW}= & 1827.23+31.35 T_{0}-35.06 e_{0}-967.82 \ln \left(T_{0}\right) \\
& -\frac{7725.26}{T_{0}}+390.92 \sqrt{e_{0}}+\frac{2372.20}{e_{0}},
\end{aligned}
$$

where $T_{0}$ and $e_{0}$ are, respectively, the air temperature $\left({ }^{\circ} \mathrm{C}\right)$ and vapor pressure $(\mathrm{hPa})$ at the screen level.

Equation (2) was developed using the dataset containing 5-min-averaged values of $\mathrm{LW}$, air temperature, and water vapor pressure, measured in São Paulo during clear-sky days. The dataset was split into two randomly selected parts (65\% and 35\%; Lütkepohl 1991). The largest part was used for development and the other one was used to test the expression. The main reason to use the 5-min-averaged values to develop the PEA is the fact that this database can capture most of the LW patterns like hourly, daily, and monthly variabilities. The final result is the parameterization that better approximates the LW data $\left(R^{2}=0.55\right)$.

In the PEA, the methodology itself is more important than the resulting expression, because this formulation is valid only for São Paulo. It should be mentioned that the nonlinear fit must be done using LW instead of the effective emissivity because, from the mathematical point of view, the diurnal variation of LW (Fig. 9a) is more suitable to interpolation than the effective emissivity (Fig. 9d). Considering that LW values are necessary, a priori, to develop the formulation, satellite data could be used in the case of absence of in situ measurements.

Table 4 presents six empirical expressions that are used to estimate the LW for clear-sky days at the surface in São Paulo (Brunt 1932; Swinbank 1963; Brutsaert 
TABLE 4. Empirical expressions used to estimate the downward atmospheric longwave radiation at the surface for clear-sky conditions. Here, $e_{0}, T_{0}$, and $\sigma$ are the water vapor pressure (hPa), air temperature (K) measured at the screen level, and Stefan-Boltzmann constant $\left(5.67 \times 10^{-8} \mathrm{~W} \mathrm{~m}^{-2} \mathrm{~K}^{-4}\right)$, respectively.

\begin{tabular}{ll}
\hline \hline \multicolumn{1}{c}{ Author (year) } & \multicolumn{1}{c}{ Expression } \\
\hline Brunt (1932) & $\left(0.52+0.065 \sqrt{e_{0}}\right) \sigma T_{0}^{4}$ \\
Swinbank (1963) & $\left(9.2 \times 10^{-6} T_{0}^{2}\right) \sigma T_{0}^{4}$ \\
Brutsaert (1975) & $1.24\left(\frac{e_{0}}{T_{0}}\right)^{1 / 7} \sigma T_{0}^{4}$ \\
Prata (1996) & $\left(1-\left[1+46.5\left(\frac{e_{0}}{T_{0}}\right)\right] \exp \left\langle-\left\{1.2+3\left[46.5\left(\frac{e_{0}}{T_{0}}\right)\right]\right\}\right.\right.$ \\
Dilley and O'Brien (1998) & {$\left[\begin{array}{l}1 / 2 \\
0\end{array} T_{0}^{4}\right.$} \\
Niemelä et al. (2001) & $59.38+113.7\left(\frac{T_{0}}{273.16}\right)^{6}+96.96 \sqrt{18.6\left(\frac{e_{0}}{T_{0}}\right)}$ \\
\hline
\end{tabular}

1975; Prata 1996; Dilley and O’Brien 1998; Niemelä et al. 2001), using MBE, RMSE, and the index of agreement $d$ (Willmott 1981), which varies between 0 and 1 and indicates the level of fitness between the estimates and measurements. It can be applied in order to make a cross comparison between the estimates and the observations (Willmott 1982). Values of $d$ close to 1 indicate a good performance of the estimates with respect to the observations:

$$
d=1-\frac{\sum_{i=1}^{N}\left(\mathrm{LW}_{i}^{\text {estimates }}-\mathrm{LW}_{i}\right)^{2}}{\sum_{i=1}^{N}\left(\left|\mathrm{LW}_{i}^{\text {estimates }}-\overline{\mathrm{LW}}\right|+\left|\mathrm{LW}_{i}-\overline{\mathrm{LW}}\right|\right)^{2}},
$$

where $\mathrm{LW}^{\text {estimates }}$ are the 5-min-averaged $\mathrm{LW}$ values estimated by the empirical expressions; $\overline{\mathrm{LW}}$ correspond to mean values of observed LW values; and $N$ indicates the number of the dataset (602 134 values).

The performance of LW expressions can be visualized in Fig. 10. All expressions overestimate the observed LW values, presenting a positive MBE. In addition, all the expressions perform better during the nighttime (Fig. $10 \mathrm{~b}$ ) because all of them are sensitive to air temperature and vapor pressure fluctuations, which are more intense through the daytime as a result of the shortwave radiation. Moreover, the PBL is shallower during the night and the effective emissivity can be better estimated by the screen parameters. Another reason for better agreement is the lack of solar heating interference in the pyrgeometer performance. As expected, the PEA expression presented the smallest MBE, RMSE, and the biggest $d$ (Fig. 10), but it is not very discrepant from Brunt's expression.

However, even the screen temperature near the surface does not totally reflect the thermal structure of the lower layers, slightly overestimating the emission during the daytime and underestimating it during the nighttime (Alados-Arboledas and Jimenez 1988; Dürr and Philipona 2004; Jonsson et al. 2006; Long and Turner 2008). The PEA better reproduces the diurnal variation of effective emissivity in the MRSP (Fig. 11). A larger degree of discrepancy in the diurnal emissivity pattern was observed for the other five expressions (not shown here).

Attempts to calibrate the six expressions improved the performance (MBE, RMSE, $d$, and closeness to the diurnal variation of effective emissivity) as expected, but none of them performed better than the PEA. Besides, there is no guarantee that expressions with the best results without calibration will provide the best fit after the procedure, bringing up questions relating to the criteria of choice. Moreover, the amount of work used to perform the calibration of one unique expression was equivalent to the entire PEA procedure, indicating that using available expressions, even when they are calibrated against local data is not the most efficient way to estimate LW under clear-sky conditions.

\section{Conclusions}

The main objective of this work was to characterize the seasonal and diurnal variation of LW in São Paulo, using 5-min-averaged measurements of LW, global, and diffuse solar radiations; air temperature; and air relative humidity carried out at the surface continuously during $9 \mathrm{yr}$, from 1997 to 2006.

A two-step filtering methodology was developed to evaluate the LW data consistency observed in São Paulo. This procedure removed about $36 \%$ of the LW observations due to sensor malfunctioning and problems in the data acquisition system. After that, the pyrgeometer dome emission effect of the LW filtered dataset was removed using the neural network technique (prior to 15 October 2003) and using the heat balance equation (after 15 October 2003). 

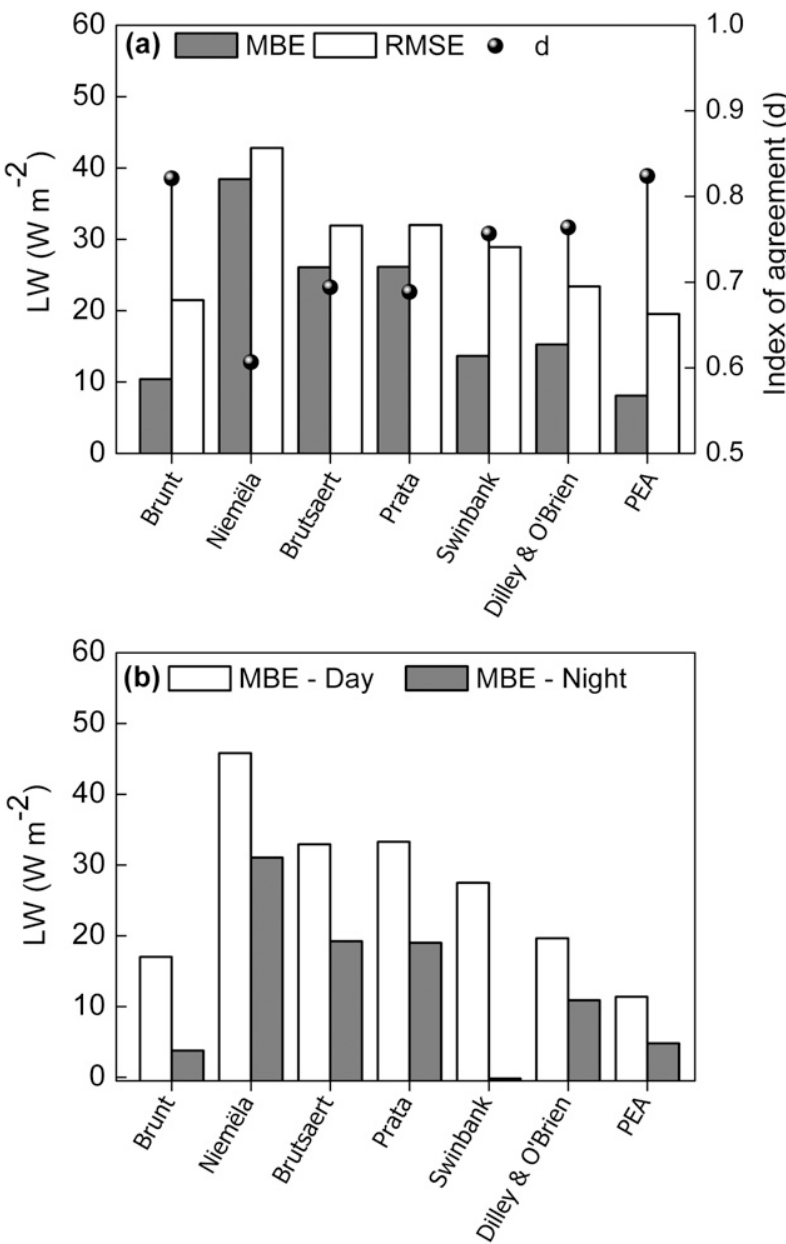

FIG. 10. Performance of the LW expressions and PEA in terms of (a) MBE (gray column), RMSE (white column), and $d$ (solid dot), for clear-sky days of the entire period; and (b) MBE for the daytime (white column) and the nighttime (gray column) periods.

Comparison between the LW observed in São Paulo and yield by the SRB project indicated a good spatial and temporal agreement for the variation of monthly and annual values. The mean MBE $\left(-12.9 \mathrm{~W} \mathrm{~m}^{-2}\right)$ and mean normalized RMSE $(3.6 \%)$ values indicate that the SRB data slightly overestimate the observed values for seasonal variation. However, this overestimate is at the same order of the errors associated with measurements and estimates. For the annual basis, the $\operatorname{MBE}\left(-14.7 \mathrm{~W} \mathrm{~m}^{-2}\right)$ and mean normalized RMSE (4.1\%) indicate that both observations and SRB are compatible from the climatological point of view. In addition, the maximum discrepancy of $\mathrm{LW}$ among the years is $16 \mathrm{~W} \mathrm{~m}^{-2}$. Therefore, the existing gaps in the dataset do not compromise the temporal representativeness of LW measurements carried out in São Paulo and one point observation can be used to represent the LW atmospheric emission in the entire

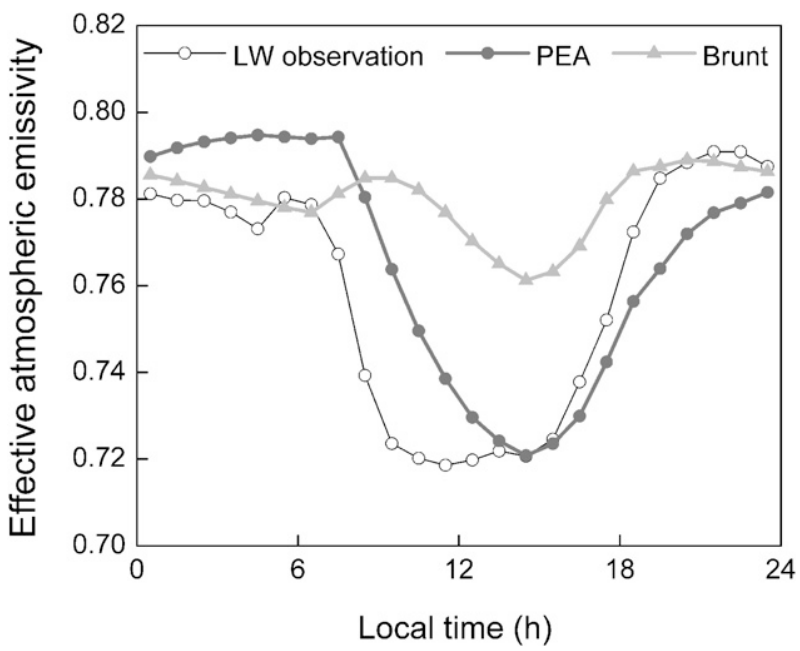

FIG. 11. Diurnal variation of effective atmospheric emissivity observed and modeled by the PEA and Brunt empirical expression estimated using monthly averaged hourly values of screen air temperature and vapor pressure observed during clear-sky days in August of the entire dataset.

MRSP. These inferences are valid only in the climatological context of monthly and annual means.

The LW observed in São Paulo shows a maximum of $398 \pm 14 \mathrm{~W} \mathrm{~m}^{-2}$ during the summer daytime (January at $1100 \mathrm{LT}$ ) and a minimum of $323 \pm 11 \mathrm{~W} \mathrm{~m}^{-2}$ during the winter daytime (June at 1000 LT). The characterizations of seasonal and diurnal variations, based on monthly averaged 5-min values of $\mathrm{LW}$, included an analysis of the mean cloud effect on the effective emissivity. This parameter conveys information about the vertical stratification of temperature and moisture that is not clearly identified in screen parameters only. Following Malek (1997) and Long and Turner (2008), mean cloud effects were successfully identified by comparing the LW observed under clear-sky conditions with the LW considering all-sky conditions. Clear-sky averages are statistically significant only between April and September when the number of clear-sky days are larger than $5 \%$. The largest number of clear-sky days occurs in August (138 days in $9 \mathrm{yr}$ ), the driest month of the year in São Paulo.

The seasonal variation of LW in São Paulo indicates that the maximum monthly averaged values of $\mathrm{LW}$ are observed during summer ( $389 \pm 14 \mathrm{~W} \mathrm{~m}^{-2}$; January) and the minimum, during winter $\left(332 \pm 12 \mathrm{~W} \mathrm{~m}^{-2}\right.$; June). Following the LW pattern, the effective emissivity, considering all days, shows a maximum in summer $(0.907 \pm 0.032$; January) and a minimum in winter $(0.818 \pm 0.029 ;$ June $)$. On average, the presence of cloud intensifies the monthly averaged values of LW by about $32.0 \pm 3.5 \mathrm{~W} \mathrm{~m}^{-2}$ and the effective emissivity at the 
surface by about $0.088 \pm 0.024 \mathrm{~W} \mathrm{~m}^{-2}$. The seasonal variation of monthly averaged hourly values of LW in MRSP reflects the combination of local climate patterns of air temperature, moisture, and clouds.

The diurnal variation of LW for clear-sky days in August shows a larger amplitude but a smaller intensity than LW for all-sky conditions, indicating that the presence of clouds not only increases the intensity of LW, but also decreases its diurnal cycle amplitude. It was shown that there is a delay (of $4 \mathrm{~h}$ in the case of August) between the daytime maximum of monthly average hourly values of LW $\left(345 \pm 12 \mathrm{~W} \mathrm{~m}^{-2}\right.$ at $\left.1800 \mathrm{LT}\right)$ and screen temperature $\left(23.2^{\circ} \pm 0.1^{\circ} \mathrm{C}\right.$ at $\left.1400 \mathrm{LT}\right)$ caused mainly by the time taking to erode the surface inversion during the morning. The diurnal variations of the effective emissivity show a minimum of $0.781 \pm$ $0.027(0.720 \pm 0.025)$ during the daytime and a maximum of $0.842 \pm 0.030(0.790 \pm 0.028)$ during the nighttime for the all-sky condition (clear-sky days). There is no apparent diurnal variation in the difference of the effective emissivity, considering all day and only clearsky conditions $(0.060 \pm 0.007)$ or about $7 \pm 1 \%$. Hence, the mean cloud effect increases the amplitude of the effective emissivity but does not alter its diurnal pattern. The effective emissivity diurnal variation is mainly modulated by the water amount variation during the end of the convective (1500-1800 LT) and nighttime periods (1800-0600 LT). During the convective period (0600$1500 \mathrm{LT})$ the effective emissivity responds to the surface inversion layer erosion and the early morning peak in the latent heat flux.

In this work, a traditional approach of applying empirical expressions to estimate the diurnal evolution of LW in clear days is investigated. The methodology is useful to better characterize the most important patterns of LW observations in clear days. It was found that empirical LW expressions available in the literature are not able to reproduce the LW in São Paulo because they cannot reproduce the diurnal variation of the effective emissivity. The reason for this mismatch is that the empirical LW expressions do not convey enough information about the diurnal variation of the thermal and moisture stratification, mainly the daytime PBL evolution. The simplest way to improve the LW estimates is using a purely empirical approach based on in situ LW measurements because it can better account for the effective emissivity diurnal cycle.

Acknowledgments. We acknowledge financial support provided by CNPq (476807/2007-7), FAPESP, and CAPES. The SRB data were obtained from the NASA Langley Research Center Atmospheric Science Data
Center. We also thank the anonymous reviewers whose comments improved the presentation of this work.

\section{REFERENCES}

Alados-Arboledas, L., and J. I. Jimenez, 1988: Day-night differences in the effective emissivity from clear skies. Bound. Layer Meteor., 45, 93-101.

Albrecht, B. A., and S. K. Cox, 1977: Procedures for improving pyrgeometer performance. J. Appl. Meteor., 16, 188-197.

Arnfield, A. J., and C. S. B. Grimmond, 1998: An urban canyon energy budget model and its application to urban storage heat flux modeling. Energy Build., 27, 1-26.

Bilbao, J., and A. H. de Miguel, 2007: Estimation of daylight downward longwave atmospheric irradiance under clear-sky and all-sky conditions. J. Appl. Meteor. Climatol., 46, 878-889.

Božnar, M., 2002: Use of neural networks in the field of air pollution modeling. Air Pollution Modeling and Its Application XV, C. Borrego and G. Schayes, Eds., Kluwer Academic, 375-383.

_ , and P. Mlakar, 1998: Improvement of air pollution forecasting models using feature determination and pattern selection strategies. Air Pollution Modeling and Its Application $X I I$, S.-E. Gryning and N. Chaumerliac, Eds., Plenum Press, $725-726$.

Brunt, D., 1932: Notes on radiation in the atmosphere. Quart. J. Roy. Meteor. Soc., 58, 389-420.

Brutsaert, W., 1975: On a derivable formula for long-wave radiation from clear skies. Water Resour. Res., 11, 742-744.

Burns, S. P., J. Sun, A. C. Delany, S. R. Semmer, S. P. Oncley, and T. W. Horst, 2003: A field intercomparison technique to improve the relative accuracy of longwave radiation measurements and an evaluation of CASES-99 pyrgeometer data quality. J. Atmos. Oceanic Technol., 20, 348-361.

Codato, G., A. P. Oliveira, J. Soares, J. F. Escobedo, E. N. Gomes, and A. D. Pai, 2008: Global and diffuse solar irradiances in urban and rural areas in southeast of Brazil. Theor. Appl. Climatol., 93, 57-73.

Crawford, T. M., and C. E. Duchon, 1999: An improved parameterization for estimating effective atmospheric emissivity for use in calculating daytime downwelling longwave radiation. J. Appl. Meteor., 38, 474-480.

Darnell, W. L., S. K. Gupta, and W. F. Staylor, 1983: Downward longwave radiation at the surface from satellite measurements. J. Climate Appl. Meteor., 22, 1956-1960.

Dilley, A. C., and D. M. O'Brien, 1998: Estimating downward clear sky long-wave irradiance at the surface from screen temperature and precipitable water. Quart. J. Roy. Meteor. Soc., 124, 1391-1401.

Duarte, H. F., N. L. Dias, and S. R. Maggiotto, 2006: Assessing daytime downward longwave radiation estimates for clear and cloudy skies in southern Brazil. Agric. For. Meteor., 139, 171-181.

Dürr, B., and R. Philipona, 2004: Automatic cloud amount detection by surface longwave downward radiation measurements. J. Geophys. Res., 109, D05201, doi:10.1029/2003JD004182.

Dutton, E. G., 1993: An extended comparison between LOWTRAN7 computed and observed broadband thermal irradiances: Global extreme and intermediate surface conditions. J. Atmos. Oceanic Technol., 10, 326-336.

Ellingson, R. G., J. Ellis, and S. Fels, 1991: Intercomparison of radiation codes used to climate models: Long wave results. J. Geophys. Res., 96, 8929-8963.

Fairall, C. W., P. O. G. Persson, E. F. Bradley, R. E. Payne, and S. P. Anderson, 1998: A new look at calibration and use of 
Eppley precision infrared radiometers. Part I: Theory and application. J. Atmos. Oceanic Technol., 15, 1229-1242.

Finch, J. W., and M. J. Best, 2004: The accuracy of downward shortand long-wave radiation at the earth's surface calculated using simple models. Meteor. Appl., 11, 33-39.

Flerchinger, G. N., W. Xaio, D. Marks, T. J. Sauer, and Q. Yu, 2009: Comparison of algorithms for incoming atmospheric longwave radiation. Water Resour. Res., 45, W03423, doi:10.1029/ 2008WR007394.

Gardner, M. W., and S. R. Dorling, 1998: Artificial neural networks (the Multiplayer Perceptron)-A review of applications in the atmospheric sciences. Atmos. Environ., 32, 2627-2636.

Garratt, J. R., 2001: Clear-sky longwave irradiance at the earth's surface-Evaluation of climate models. J. Climate, 14, 1647-1670.

Gröbner, J., S. Wacker, L. Vuilleumier, and N. Kämpfer, 2009: Effective atmospheric boundary layer temperature from longwave radiation measurements. J. Geophys. Res., 114, D19116, doi:10.1029/2009JD012274.

Gupta, S. K., W. L. Darnell, and A. C. Wilber, 1992: A parameterization for longwave surface radiation from satellite data: Recent improvements. J. Appl. Meteor., 31, 1361-1367.

_ A. C. Wilber, W. L. Darnell, and J. T. Suttles, 1993: Longwave surface radiation over the globe from satellite data: An error analysis. Int. J. Remote Sens., 14, 95-114.

- , N. A. Ritchey, A. C. Wilber, C. H. Whitlock, G. G. Gibson, and P. W. Stackhouse Jr., 1999: A climatology of surface radiation budget derived from satellite data. J. Climate, 12, 2691-2710.

Iziomon, M. G., H. Mayer, and A. Matzarakis, 2003: Downward atmospheric longwave radiation under clear and cloudy skies: Measurement and parameterization. J. Atmos. Sol. Terr. Phys., 65, 1107-1116.

Ji, Q., and S.-C. Tsay, 2000: On the dome effect of Eppley pyrgeometers and pyranometers. Geophys. Res. Lett., 27, 971-974.

Jonsson, P., I. Eliasson, B. Holmer, and C. S. B. Grimmond, 2006: Longwave incoming radiation in the tropics: Results from field work in three African cities. Theor. Appl. Climatol., 85, 185-201.

Karam, H. A., A. J. Pereira-Filho, V. Mason, J. Niolhan, and E. P. Marques-Filho, 2009: Formulation of tropical town energy budget (t-TEB) scheme. Theor. Appl. Climatol., 100,1-10.

Long, C. N., and D. D. Turner, 2008: A method for continuous estimation of clear-sky downwelling longwave radiative flux developed using ARM surface measurements. J. Geophys. Res., 113, D18206, doi:10.1029/2008JD009936.

Lütkepohl, H., 1991: Introduction to Multiple Time Series Analysis. Springer Verlag, $545 \mathrm{pp}$.

Malek, E., 1997: Evaluation of effective atmospheric emissivity and parameterization of cloud at local scale. Atmos. Res., 45, 41-54.

Marciotto, E. R., 2008: Estudo da influência de um dossel urbano sobre o balanço de energia na superfície e implicações na estrutura vertical da camada limite atmosférica. Tese de Doutorado. Departamento de Ciências Atmosféricas, Instituto de Astronomia, Geofísica e Ciências Atmosféricas, Universidade de São Paulo, São Paulo, SP, Brasil, 120 pp. [Available online at http://www.iag.usp.br/meteo/labmicro/publicacoes/Teses\& Dissertacoes/Marciotto_2008_Estudo_da_influencia_de_um dossel_urbano_sobre_o_balanco_de_energia_na_superficie_e implicacoes_na_estrutura_vertical_da_camada_limite_atmosferica. pdf.]

Martilli, A., A. Clappier, and M. W. Rotach, 2002: An urban surface exchange parameterization for mesoscale models. Bound. Layer Meteor., 104, 261-304.
Marty, C., and Coauthors, 2003: Downward longwave irradiance uncertainty under Arctic atmospheres: Measurements and modeling. J. Geophys. Res., 108, 4358, doi:10.1029/ 2002JD002937.

Mlakar, P., and M. Božnar, 1997: Perceptron neural network-based model predicts air pollution. Proc. Intelligent Information Systems IIS'97, Grand Bahama Island, Bahamas, IEEE Computer Soc., 345-349.

Mlawer, E. J., S. J. Taubman, P. D. Brown, M. J. Iacono, and S. A. Clough, 1997: Radiative transfer for inhomogeneous atmospheres: RRTM, a validated correlated-k model for the longwave. J. Geophys. Res., 102 (D14), 16 663-16 682.

Nair, K. N., E. D. Freitas, O. R. Sánchez-Ccoyllo, M. A. F. Silva Dias, P. L. Silva Dias, M. F. Andrade, and O. Massambani, 2004: Dynamics of urban boundary layer over São Paulo associated with mesoscale processes. Meteor. Atmos. Phys., 86, 87-98.

Niemelä, S., P. Räisänen, and H. Savijärvi, 2001: Comparison of surface radiative flux parameterizations Part I: Longwave radiation. Atmos. Res., 58, 1-18.

Offerle, B., C. S. B. Grimmond, and T. R. Oke, 2003: Parameterization of net all-wave radiation for urban areas. J. Appl. Meteor., 42, 1157-1173.

Oliveira, A. P., E. J. Escobedo, and A. J. Machado, 2002a: A new shadow-ring device for measuring diffuse solar radiation at surface. J. Atmos. Oceanic Technol., 19, 698-708.

,,$-- \ldots$, and J. Soares, 2002b: Diurnal evolution of solar radiation at the surface in the City of São Paulo: Seasonal variation and modeling. Theor. Appl. Climatol., 71, 231-249.

, R. Bornstein, and J. Soares, 2003: Annual and diurnal wind patterns in the city of São Paulo. Water Air Soil Pollut. Focus, 3, 3-15.

, J. Soares, M. Z. Božnar, P. Mlakar, and J. F. Escobedo, 2006: An application of neural technique to correct the dome temperature effects on pyrgeometer measurements. J. Atmos. Oceanic Technol., 23, 80-89.

Payne, R. E., and S. P. Anderson, 1999: A new look at calibration and use of Eppley precision infrared radiometers. Part II: Calibration and use of the Woods Hole oceanographic institution improved meteorology precision infrared radiometer. J. Atmos. Oceanic Technol., 16, 739-751.

Pérez, M., and L. Allados-Arboledas, 1999: Effects of natural ventilation and solar radiation on the performance of pyrgeometers. J. Atmos. Oceanic Technol., 16, 174-180.

Philipona, R., C. Fröhlich, and C. Betz, 1995: Characterization of pyrgeometers and the accuracy of atmospheric long-wave radiation measurements. Appl. Opt., 34, 1598-1605.

-, and Coauthors, 2001: Atmospheric longwave irradiance uncertainty: Pyrgeometers compared to an absolute sky-scanning radiometer, atmospheric emitted radiance interferometer, and radiative transfer model calculations. J. Geophys. Res., 106 (D22), 28 129-28 141.

— B. Bür, and C. Marty, 2004: Greenhouse effect and altitude gradients over the Alps-By surface longwave radiation measurements and model calculated LOR. Theor. Appl. Climatol., 77, 1-7.

Prata, A. J., 1996: A new long-wave formula for estimating downward clear-sky radiation at the surface. Quart. J. Roy. Meteor. Soc., 122, 1127-1151.

Snedecor, G. W., and W. G. Cochran, 1989: Statistical Methods. 8th ed. Iowa State University Press, 503 pp.

Soares, J., A. P. Oliveira, M. Z. Boznar, P. Mlakar, J. F. Escobedo, and A. J. Machado, 2004: Modeling hourly diffuse solar 
radiation in the city of São Paulo using neural network technique. Appl. Energy, 79, 201-214.

Swinbank, W. C., 1963: Long-wave radiation from clear skies. Quart. J. Roy. Meteor. Soc., 89, 339-348.

Targino, A. C. L., and J. Soares, 2002: Modeling surface energy fluxes for Iperó, SP, Brazil: An approach using numerical inversion. Atmos. Res., 63, 101-121.

Turner, D. D., and Coauthors, 2004: The QME AERI LBLRTM: A closure experiment for downwelling high spectral resolution infrared radiance. J. Atmos. Sci., 61, 2657-2675.
Wilber, A. C., G. L. Smith, S. K. Gupta, and P. W. Stackhouse Jr., 2006: Annual cycles of surface shortwave radiative fluxes. J. Climate, 19, 535-547.

Wilks, D. S., 2006: Statistical Methods in the Atmospheric Sciences. 2nd ed. International Geophysics Series, Vol. 91, Academic Press, 648 pp.

Willmott, C. J., 1981: On the validation of models. Phys. Geogr., 2, 184-194.

_ 1982: Some comments on the evaluation of model performance. Bull. Amer. Meteor. Soc., 63, 1309-1313. 